\title{
Effect of Aqueous Extract of Phoenix dactylifera Pollen on Dopamine System of Nucleus Accumbens in Male Rats
}

\author{
Ali Abedi' ${ }^{1}$, Seyyed Morteza Karimian², Mohsen Parviz ${ }^{2}$, Perham Mohammadi ${ }^{3}$, \\ Hamid Reza Sadeghipour Roudsari ${ }^{2 *}$ \\ ${ }^{1}$ Physiology Department, Faculty of Medicine, Ardabil University of Medical Sciences, Ardabil, Iran \\ ${ }^{2}$ Physiology Department, Faculty of Medicine, Tehran University of Medical Sciences, Tehran, Iran \\ ${ }^{3}$ Pharmacology Department, School of Pharmacy, Ardabil University of Medical Sciences, Ardabil, Iran \\ Email: Sadeghipour@sina.tums.ac.ir
}

Received 30 January 2014; revised 28 February 2014; accepted 15 March 2014

Copyright (C) 2014 by authors and Scientific Research Publishing Inc.

This work is licensed under the Creative Commons Attribution International License (CC BY).

http://creativecommons.org/licenses/by/4.0/

(c) (i) Open Access

\begin{abstract}
Background: Dopamine has been known to facilitate male sexual function. Methods: The effect of aqueous extract $(140 \mathrm{mg} / \mathrm{kg})$ of Phoenix dactylifera date palm pollen on sexual behavior and determining of dopamine transmission in the nucleus accumbens was studied in male rats using in vivo microdialysis. Results: Releasing of dopamine increased significantly in the nucleus accumbens when a receptive female was introduced behind a screen $(p<0.001)$. During copulation, dopamine increased markedly in control and treated rats. Phoenix dactylifera Date Palm Pollen enhanced the orientation of males towards females by increasing mounting and ano-genital investigatory behavior. Improving of sexual behavior and dopamine release was higher in treated rats in comparison with control $(\mathbf{p}<\mathbf{0 . 0 0 1})$. Conclusion: These results indicate a neurochemical basis for interaction between dopaminergic agents and male sexual behavior. Therefore, Phoenix dactylifera Date Palm Pollen seems to act as a dopamine agonist and to cure male infertility. It can be used as an aphrodisiac that leads to further increases in dopamine release.
\end{abstract}

\section{Keywords}

Phoenix dactylifera; Date Palm Pollen; Dopamine; Nucleus Accumbens; Microdialysis; Male Rat

\section{Introduction}

Male sexual behavior comprises a complex pattern of genital and somatomotor responses, elicited, directed, and

${ }^{*}$ Corresponding author.

How to cite this paper: Abedi, A., Karimian, S.M., Parviz, M., Mohammadi, P. and Roudsari, H.R.S. (2014) Effect of Aqueous Extract of Phoenix dactylifera Pollen on Dopamine System of Nucleus Accumbens in Male Rats. Neuroscience \& Medicine, 5, 49-59. http://dx.doi.org/10.4236/nm.2014.51008 
maintained by external and internal signals. These include copulation and precopulatory behaviors that allow the male to detect and locate a mate, assess her potential mating appropriateness, and stimulate a receptive response [1]. In sexual behavior, there is a change in the release manner or effect of one or more neurotransmitters. One of these is dopamine (DA), since dopaminergic agonists have long been known to facilitate sexual function [2]. However, the exact involvement of dopamine in control of sexual motivation and genital arousal in males is unknown [3].

Dopamine (DA), releases in several major integrative areas before and/or during copulation, and facilitates sexual motivation, motor performance, and genital reflexes [4]. Dopamine has been known to facilitate male sexual function. L-Dopa (the precursor of DA) administered to parkinsonian patients increases libido and sexual potency [5], and the nonspecific DA agonist apomorphine has been used to treat sexual dysfunction [2] [6] [7].

In rats, DA agonists facilitate male sexual behavior [3] [8] [9], induce sexually sluggish males to copulate [10], elicit copulation in sexually exhausted males [11], and partially restore copulation in castrated rats [12]. Systemically administration of DA antagonists impairs sexual behavior in both sexually experienced and naive rats [13] [14]. The negative effects of DA antagonists range from increased Intromission Latency (IL) and Ejaculation Latency (EL) to failure to copulate [3]. Haloperidol (a nonspecific DA antagonist) inhibits measures of sexual motivation as well as copulation itself [15] [16]. In human males, DA antagonists reduce sexual desire, arousal, and orgasm [17].

DA receptors are classified into two families-the D1-like family includes receptors positively coupled to adenylyl cyclase and comprises the D1 and D5 receptor subtypes, while the D2-like family consists of D2, D3 and D4 receptor subtypes, which are negatively coupled to adenylyl cyclase [3] [18].

At the supraspinal level, DA has a facilitative effect on ejaculation, mediated especially in the Medial preoptic area (mPOA) and Paraventricular nucleus of the hypothalamus (PVN) by D2-like receptors [19] [20].

Systemic activation of D2-like receptors facilitates the ejaculation by decreasing both intromission frequency (IF) and ejaculation latency (EL) in sexually experienced rats. In anesthetized rats, intra-mPOA injection of a D3 agonist can induce bulbospongiosus rhythmic contractions and ejaculation [21] [22].

Thus, supraspinal command of ejaculation appears to be mediated by D2-like receptors, probably of the D3 subtype, in the mPOA. D1-like receptor agonists increased sexual motivation in rats [23] [24]. The effects of DA agonists are dose-dependent. Low-dose of DA agonists facilitates the copulation and high-dose inhibits the copulation. The latter effect is possibly due to the induction of stereotypic behavior [25] [26]. Contradictory effects of D1- and D2-like receptor agonists on ex copula genital reflexes have been reported. D2-selective agonists elicit erection, while a D1-receptor agonist inhibits erection [27].

Steroid hormones facilitate sexual behavior by biasing sensorimotor integration so that a sexually relevant stimulus is more likely to elicit a sexual response. Most steroid effects that are important for the elicitation of sexual behavior are mediated by slow genomic actions [28] [29], although steroids also have rapid, nongenomic effects [30] [31]. Among the important targets of steroid action, there are synthetic enzymes, receptors, or other proteins affecting neurotransmitter function.

A variety of plants derivations have been used as sex stimulants in the traditional medicine around the world especially in Asia and Africa. Date palm (Phoenix dactylifera L., Palmae) is native to the Middle East region over centuries ago. In traditional medicine, date represents an essential meal in some Arab area. Pollen of the date palm has been used for thousands of years as a traditional herbal medicine for improving male and female fertility. Extracts of fruits, pits and edible kernels showed improvement of vital activities and increased the hormonal concentration in rats. Phytochemical studies of DPP showed the presence of estrone, $\alpha$-amirin, triterpenoidal saponins, flavonoids and a crude gonadotrophic substance, and also revealed the presence of estrone, estradiol and estriol, besides five flavonoids compounds.

Only few studies have been conducted to prove its fertility improving effects in males. One study showed its functional health benefits on sperm parameters and reproductive system of adult male rats and the other shed light on its protective effect on cisplatin-induced male infertility in rats. Suspension of Pheonix dactylifera date palm pollen (DPP) is an herbal mixture that is used to restore sexual potency and to cure male infertility in traditional medicine [32] [33]. However, there are no scientific data on the effect of DPP on male sexual behavior and the role of dopamine on it in male rats. Therefore, the present study examined changes in central DA transmission in the nucleus accumbens (NAc) in sexually experienced male rats following injection of aqueous extract of DPP. 


\section{Methods and Materials}

In our previous study, the maximum effect of DPP observed in dose $140 \mathrm{mg} / \mathrm{kg}$ [34], therefore, we used this dose for measuring of the dopamine level in nucleus accumbens.

Samples of male Date pollen grain obtained from botanical garden at Bushehr Province (South of IRAN).

\subsection{Preparation of Extract}

Pollen grains washed with distilled water and then dried. The dried pollen grain pulverized with a small electric blender. The powder extracted in warm distilled water with constant shaking. The solution passed through a filtrate paper and lyophilized. After vaporizing the water, solution with dose $140 \mathrm{mg} / \mathrm{kg}$ prepared in the mixture of normal saline and Dimethyl Sulphate (DMSO) for injection. For preventing of pollution, solution stored in a refrigerator $\left(2^{\circ} \mathrm{C}-8^{\circ} \mathrm{C}\right)$. A volume of $0.2 \mathrm{ml} /$ rat/injected one hour prior to test (IP).

\subsection{Animals}

The study adheres to the principles of laboratory care established by Ethic Committee of Tehran University of Medical Sciences. Healthy male rats (wistar albino), 4 months old, weighting between 280 - 320 g and females, 3 months old weighting between 220 - 250 g selected from our department animal house (Physiology Department of Tehran University of Medical Sciences). The animals separated by sex and housed in a plexy glass cage (4 in each cage) placed in well-ventilated animal house. Room temperature was $22^{\circ} \mathrm{C} \pm 2{ }^{\circ} \mathrm{C}$ with humidity of 60\%. Animals maintained in a reversed light-dark cycle (light on 7 p.m. - 7 a.m.). The animals were acclimated for about 4 weeks before the experimentation. They allowed access to food pellets and tab water ad libitum. Experiments were done in dark period under red light.

Female rats used as mating stimulus. They anesthetized with ketamine (100 mg/kg I.P.) and xylazine (10 $\mathrm{mg} / \mathrm{kg}$ I.P.) and bilaterally ovariectomnized by making an incision in abdomen area. After recovery, behavioral estrus induced by sequential subcutaneous injection of estradiol benzoate (10 $\mu \mathrm{g} / 100 \mathrm{gr}$ body weight S.C.) and progesterone (500- $\mu \mathrm{g}$ body weight S.C.), 52 and 4 hours, respectively before each test.

\subsection{Surgery and Microdialysis Probes}

Sexually experienced male rats anesthetized with ketamine hydrochloride (100 mg/100g I.P.) and xylazine (10 $\mathrm{mg} / 100 \mathrm{~g}$ I.P.) and implanted with a vertically oriented microdialysis probe into the nucleus accumbens by streotaxe apparatus (Harvard Co.). The skull surface was exposed and holes drilled. A vertically oriented probe was implanted with the following specifications: AP: $+2.52 \mathrm{~mm}, \mathrm{ML}:+1.4 \mathrm{~mm}$ and DV: $-6.8 \mathrm{~mm}$ according to the atlas of Paxinos [35]. Each probe secured with dental acrylic to the three anchoring screws, and the skin sutured. The dialysis probes were a modified one that made by us. Needles with gauge 30 (OD: $0.3 \mathrm{~mm}$ ) and 17 (ID: $0.6 \mathrm{~mm}$ ) were used for making probes. G17 needle used as guide cannula and G30 needle as inlet and outlet that introduced directly into the cannula. The length of inlet and outlet tubes was $0.80 \mathrm{~mm}$ larger than cannula. Following surgery, the males housed individually in a Perspex cage with Food and water available at libitum. An antibiotic drug was injected (IM) for prevention of infection.

Test of male sexual behavior and microdialysis was done four days after surgery. Implanted male rat placed in a Perspex cage $(30 * 40 * 50 \mathrm{~cm})$ that located on a metal box and a mirror was located in an oblique position in it. The cage had a mesh plate in middle that divided the cage into two equal compartments.

The inlet cannula of dialysis probe connected to a perfusion pump and the outlet connected to a vacuum syringe via a polyethylene tube (PE-10). Perfusion was done with a Ringer's solution (147 mM NaCl, $3 \mathrm{mM} \mathrm{KCl}$, $1.3 \mathrm{mM} \mathrm{CaCl}_{2}, 1 \mathrm{mM} \mathrm{MgCl}_{2}$, and $1.5 \mathrm{mM} \mathrm{NaPO}_{4}, \mathrm{pH}=7.3$ ) at a flow rate of $5 \mu \mathrm{l} / \mathrm{min}$.

\subsection{Groups of Implanted Rats}

Twenty four implanted male rats were grouped into three (A - C) consisting of eight animals each. Group A were control. Group B received normal saline and DMSO (vehicle) and Group C were treated with dose $140 \mathrm{mg} / \mathrm{kg}$ of aqueous extract mixed with saline and DMSO (IP). Tests on implanted rats were done one hour after injection.

Duration of test was a period of 70 minutes. Samples collected each 10 minutes from nucleus accumbens and sexual behavior parameters measured by camera and direct observation. 
For the first 10 minutes, male rat was restricted to one-half of the cage and collection of samples gathered. After 10 minutes, a receptive female placed on the other side of cage (anticipatory phase). 10 minutes later, the screen separator removed and sexual interaction allowed for 30 minutes (consummatory phase). During this time, the number of mounts, intromissions, ejaculations and their latencies recorded. At the end of this period, female separated by mesh plate for 10 minutes and at the final 10 minutes, female removed. Effluent samples collected over 10 minutes period for measuring dopamine and sexual behaviors recorded only in consummatory period. After collecting of samples, they preserved in $-20^{\circ} \mathrm{C}$. After each test, rats received $2 \mu$ injection of blue ink and then were decapitated for removing their brains. Data from animals with injections sites inside the nucleus accumbens used. In control group, and at the end of experiment, the same female was introduced again and DA level was measured. After 10 minutes, another female was placed instead of previous female and DA level was measured.

Dopamine level measured by means of kit (ABO Switzerland Co.). For this, original density standard diluted, and then sample added and incubated for 30 minutes at $37^{\circ} \mathrm{C}$. After 5 times washing, HRP-conjugate reagent was added and incubated for 30 minutes at $37^{\circ} \mathrm{C}$. Finally, chromagen solution A and B added and their absorbance read at $450 \mathrm{~nm}$ within 15 minutes by ELISA reader and calculated. Concentration of dopamine expressed in $\mathrm{pg} / 10 \mu \mathrm{l} / 10 \mathrm{~min}$ of sample.

Sexual behavior parameters of male rats were as following: 1-Mount Latency (ML), time from introduction of the female until the first mount. 2-Intromission Latency (IL), time from introduction of the female until the first intromission. 3-Ejaculation Latency (EjL), time from the first intromission until ejaculation. 4-Mount Frequency (MF), the number of mounts in a series. 5-Intromission Frequency (IF), the number of intromissions in a series. 6-Ejaculation Frequency (EjF), the number of times there was expulsion of semen by males after vaginal penetration-characterized by rhythmic contraction of the posterior abdomen [36]. Mating tests terminated when there was no ejaculation within consummatory period.

\subsection{Statistical Analysis}

After recording the sexual behavioral parameters, Data expressed as Mean \pm SED and analyzed. The DA Data analyzed using between-within ANOVA to assessment of an intraction. Tukey HSD analysis applied to camparison DA level in each group and across periods. The comparison of means between control and each experimental group was done by the Wilcoxon-test. $\mathrm{p}<0.05$ was regarded as significant and SPSS software version 17 used for analyzing.

\section{Results}

The sexual behaviors results of experiments summarized in Table 1. The extract produced no obvious sedative effects and no changes on respiration or heart rate in male rats. The proceptive female rats displayed ear-wiggling, rapid anteroposterior vibration of the ears, a short run and presenting her posterior to the male rats (darting) and a short jump with stiff legs and immobility and hopping. The male rats displayed precopulatory behaviour such as chasing, anogenital sniffing which eventually culminated into mounting. Lordosis displayed by the receptive female rats before, at the beginning and during the mounts. Differences of parameters between control and saline treated group were not significant. The aqueous extract had significant effect $(p<0.001)$ on all parameters. MF, IF, EjF and EjL increased, while ML and IL decreased in treated animals in comparison with control $(\mathrm{p}<0.001)$. Orientations of male towards the female rats were more frequent and vigorous in treated rats.

The computed male sexual behaviour parameters which included percentages of index of libido, mounted, intromitted, ejaculated and copulatory efficiency were higher in the extract-treated animals compared to the untreated control animals. These indexes were statistically significant $(\mathrm{p}<0.001)$.

Basal concentration of DA (Mean \pm SEM) for control and saline treated groups were $18.702 \pm 0.618$ and $18.936 \pm 0.647 \mathrm{pg} / \mu \mathrm{l}$, respectively while for extract treated was $37.809 \pm 0.124 \mathrm{pg} / \mu \mathrm{l}$. Differences between saline treated and control groups were not significant. DA level change of extract treated group was significant in comparison with control group ( $\mathrm{p}<0.001)$ (Figure 1).

DA level, increased in the $2^{\text {nd }}$ phase (time 20), in three groups. DA concentration in control and treated rats was $30.38 \pm 0.257$ and $53.04 \pm 0.398 \mathrm{pg} / \mu \mathrm{l}$, respectively. Differences between control and treated groups were significant $(\mathrm{p}<0.001)$ (Figure 1). 
Table 1. Effect of DPP on sexual behavior of male rats in 3 groups.

\begin{tabular}{cccc}
\hline Groups $\rightarrow$ & Control & Vehicle & Treated (140 mg $/ \mathrm{kg})$ \\
\hline Parameters & Mean \pm SEM & Mean \pm SEM & Mean \pm SEM \\
\hline Mount Latency (ML) (Sec.) & $230 \pm 24.69$ & $231 \pm 23.15^{*}$ & $99 \pm 14.49^{* * * *}$ \\
Intromission Latency (IL) (Sec.) & $334 \pm 24.68$ & $335 \pm 26.05^{*}$ & $182 \pm 11.35^{* * *}$ \\
Ejaculation Latency (EJL) (Sec.) & $232 \pm 21.83$ & $230 \pm 20.85^{*}$ & $387 \pm 21.10^{* * *}$ \\
Mount Frequency (MF) & $10.2 \pm 1.47$ & $10.5 \pm 1.64^{*}$ & $28.3 \pm 2.35^{* * *}$ \\
Intromission Frequency (IF) & $6.9 \pm 1.19$ & $6.7 \pm 1.25^{*}$ & $18.6 \pm 2.31^{* * *}$ \\
Ejaculation frequency (EJF) & $3.2 \pm 0.81$ & $3.1 \pm 0.76^{*}$ & $13.2 \pm 2.25^{* * *}$
\end{tabular}

Values are expressed in means \pm SEM. All frequencies and Intervals recorded during the consummatory phase. Significant from control: ${ }^{*}$ non- significant; ${ }^{* * *} \mathrm{p}<0.001$.

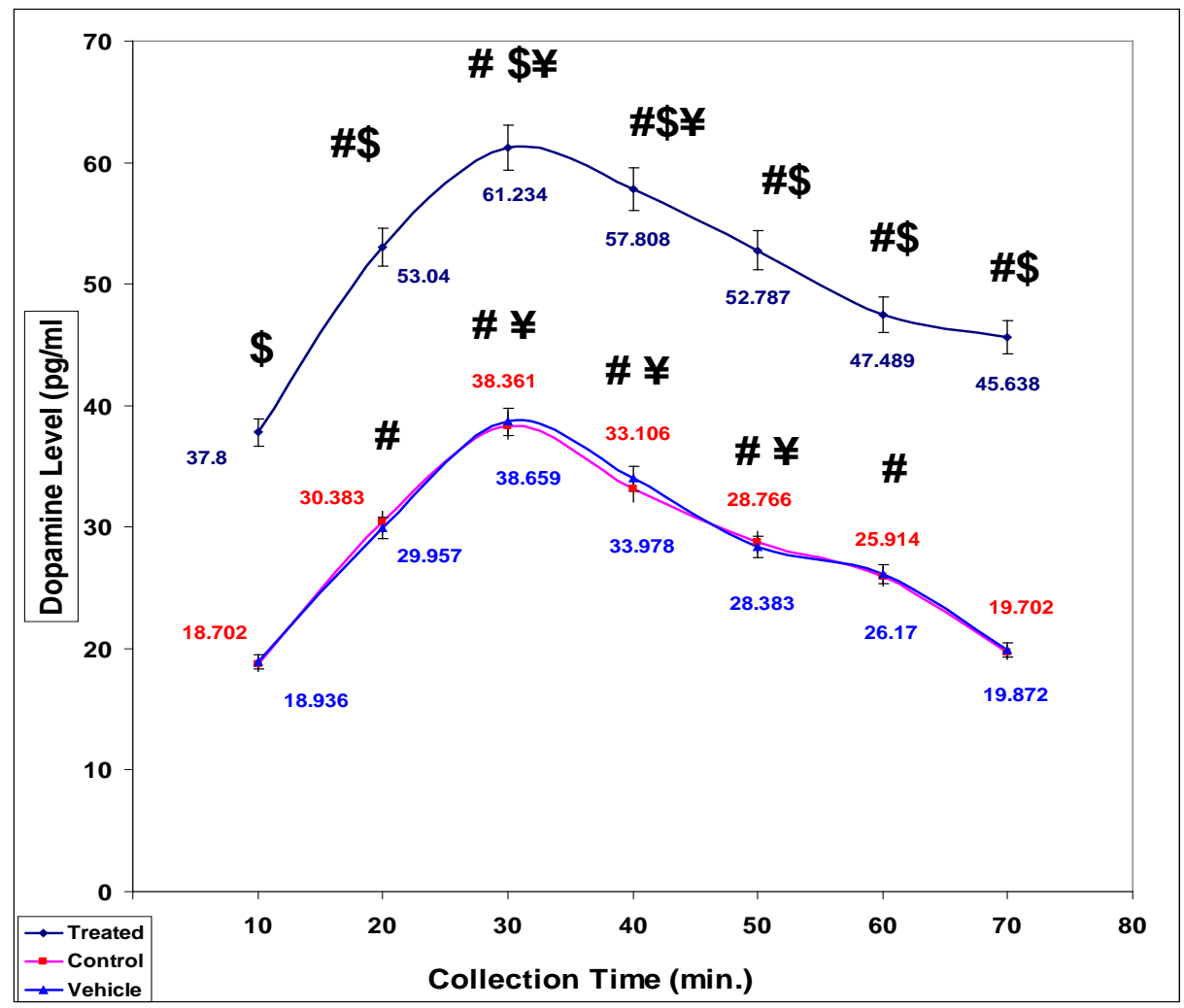

CP: Cunsummatory Phase, AP: Anticipatory Phase. "Statistically significant in comparison with baseline in 3 groups $(\mathrm{p}<0.001) .{ }^{\$}$ Statistically significant in comparison with the same time of control $(\mathrm{p}<0.001)$. ${ }^{\mathrm{V}}$ Statistically significant in comparison with other times in 3 groups $(\mathrm{p}<0.001)$.

Figure 1. Changes (Mean \pm SEM) in dialysis concentration of dopamine (pg/ $\mu \mathrm{l})$ taken from nucleus accumbens of male rats in 3 groups.

In control group, DA level in time 30, 40, 50, 60 and 70 was $38.36 \pm 0.208,33.11 \pm 0.269,28.77 \pm 0.233$, $25.91 \pm 0.185$ and $19.7 \pm 0.212 \mathrm{pg} / \mu \mathrm{l}$, respectively. Tukey HSD analysis showed that the differences of DA level, in all times (except time 70 ) was statistically significant in comparison with baseline $(\mathrm{p}<0.001)$.

In treated group, DA level in time 30, 40, 50, 60 and 70 was $6123 \pm 0.186,57.81 \pm 0.236,52.79 \pm 0.491$, $47.49 \pm 0.603$ and $45.64 \pm 0.774 \mathrm{pg} / \mu \mathrm{l}$, respectively Tukey HSD analysis showed that the differences of DA level, in all times (except time 70) was statistically significant in comparison with baseline $(p<0.001)$.

ANOVA analysis for three groups showed that, DA levels within groups was statistically significant $(\mathrm{p}<$ 
0.001) and the differences of DA level in treated group was significant in comparison with the same time in control $(\mathrm{p}<0.001)$.

In all groups, DA levels increased following replacing a female on the other side of cage and following mating with a receptive female. Then, DA concentration gradually decreased after separating of female. In all phases, DA concentration was higher in extract treated rats in comparison with control $(\mathrm{p}<0.001)$. Maximum level of DA observed in the consummatory phase (Figure 1).

Sexually active male rats transferred to mating chamber. A receptive female introduced into the mating cage after 10 minutes. $10 \mathrm{~min}$ later, the screen removed and rats copulated (30 $\mathrm{min}$ ). $30 \mathrm{~min}$ later, female separated by hindrance and after $10 \mathrm{~min}$, female removed. At the end of $70 \mathrm{~min}$, the same female introduced, and 10 min later replaced with a new female. Finally, microdialysis of male continued to the end of $90 \mathrm{~min}$.

In control group and at time 80, DA level increased but the increasing of DA level was not significant in comparison with base. But, in time 90, DA level increased that the differences was significant in comparison with base (time 10) (Figure 2).

\section{Discussion}

After putting a male rat into the mating cage, active exploratory behavior such as locomotion, sniffing and rearing observed in all groups. Both rats tried to investigate each other after placing receptive female behind the mesh wall. Following removing the mesh wall, sexual behavior started throughout the 30-min period (Table 1). Results showed a significant increase in penile erection and genital grooming and these parameters was greater in treated male rats. Increasing of penile erection induced by DPP could be due to its androgenic effects. Androgens are essential for normal penile erection and it regulates the magnitude of penile erectile response by increasing of cavernous blood flow [37] [38]. In this study, mounting, intromission, ejaculation latencies and frequencies changed significantly in treated rat in comparison with control group that may be due to the androgenic effect of DPP [33]. These results support the use of DPP as aphrodisiac and treatment of premature ejaculation in traditional medicine.

DA output in nucleus accumbens increased significantly when a female was introduced behind the mesh (anticipatory phase) in all groups, and it was greater in treated rats. There are significant increases in DA release in the nucleus accumbens of male rats during their first encountering with receptive females in three groups. This appears to be an unconditional event. Increasing of DA may be due to releasing of female pheromones [39] [40]. After removing of screen wall and during the consummatory phase of sexual behavior, a significant increase of DA observed and gradually decreased that indicating dissociation between DA and motor activity. DA concentration of nucleus accumbens increased markedly following administration of DPP in two phases of sexual behavior. The rise of DA release was smaller in control group. These results indicate that, copulation stimulate meso-accumbens DA release and suggest that mounting with intromission are associated with DA of NAc [4]. The nucleus accumbens (NAc) is a brain region involved in various functions ranging from motivation and reward to feeding and drug addiction. The NAc divides into two major subdivisions, the shell and the core. The primary output neurons of both of these areas are medium spiny neurons (MSNs), which are quiescent at rest and depend on the relative input of excitatory and inhibitory synapses they will fire action potentials. These synaptic inputs, in turn, regulated by a number of neurochemical signaling agents that can ultimately influence information processing in the NAc [41]. Meso-accumbens projection is important and critical in neural activity and incentive motivation [4]. These data indicate that copulation elicits mesolimbic DA release unconditionally in male rats and mountings with intromissions are associated with increases in accumbens DA [42].

Mesolimbic system provides the motivational impetus. Decreasing mesolimbic dopamine activity delayed the onset and slowed the rate of copulation [19]. It also led to general inactivity and poorly organized copulatory patterns, but did not affect specifically sexual motivation. Thus, general activation, but not specifically sexual motivation, may be affected by mesolimbic activity [19] [42].

DA facilitates male sexual function. Analysis of DPP showed that it contains high amount of sterols, steroids, alkaloids and flavonoids [43]-[45] [40] [46] that these agents can improve and regulate sexual behavior. It may be logical to attribute these behaviors to flavonoid constituents of the DPP since they alter androgen levels. Alkaloid content of DPP appears to have ergogenic properties by inducing vasodilatation of blood vessels, which happens in erection. They have genomically mediated effects and can enhance the processing of sensory stimuli, altering the synthesis of receptors and neurotransmitters in integrative area of brain and increase the responsive- 


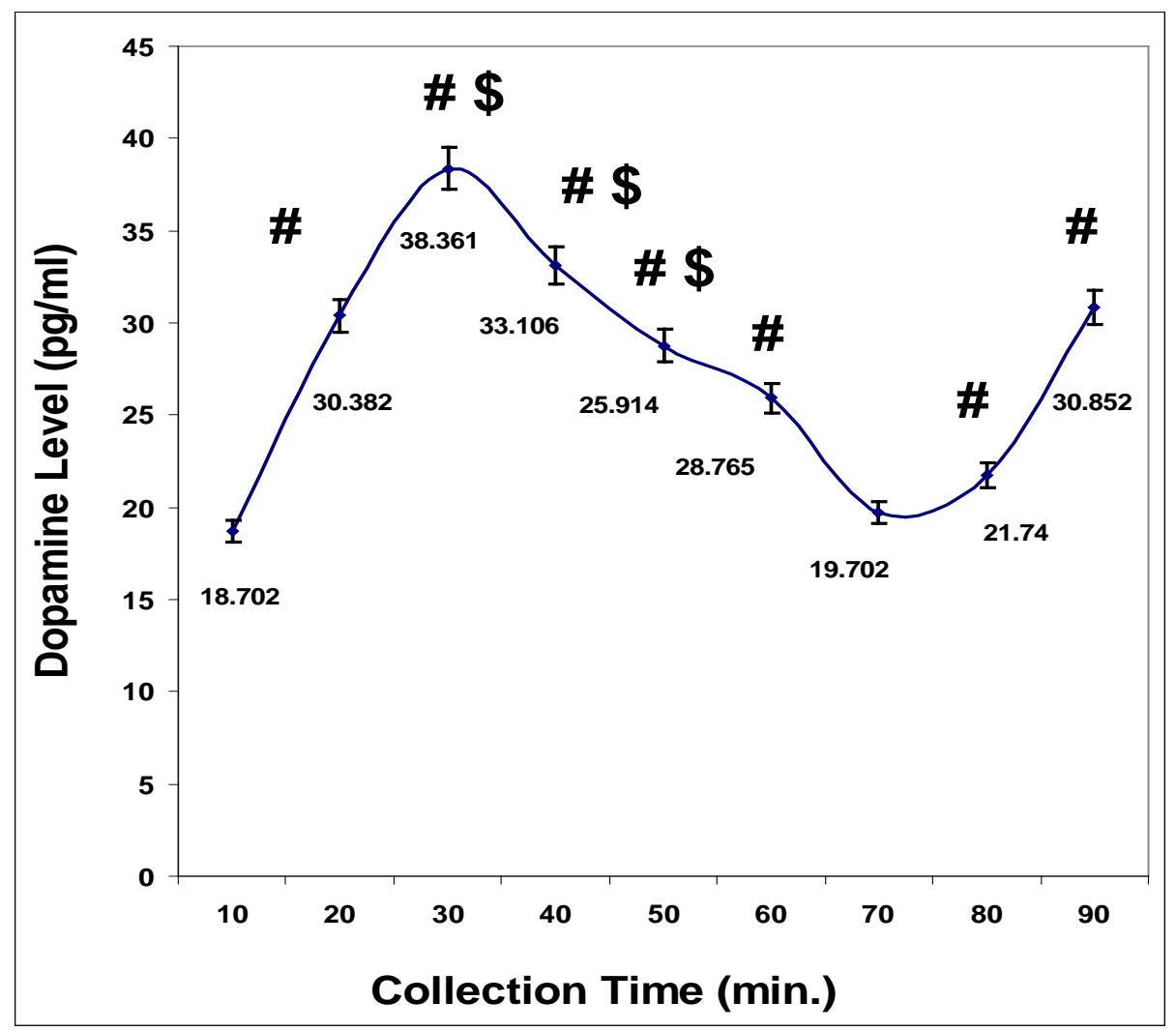

M = Male, F = Female, NF = New Female. MF: Anticipatory Phase, M + F: Cunsummatory Phase. ${ }^{\#}$ Statistically significant in comparison with baseline $(\mathrm{p}<0.001)$. ${ }^{\$}$ Statistically significant in comparison with other times $(\mathrm{p}<$ 0.001).

Figure 2. Changes (Mean \pm SEM) in dialysis concentration of dopamine (pg/pl) taken from nucleus accumbens of male rats in control group.

ness of motor output. DA has a facilitative effect on sexual behavior and DA agonist can enhance this process [47].

The pattern of accumbal DA release observed in this study which indicates that two distinct phases occur, during sexual activity in male rats: a mild response to primary or secondary sexual incentives (anticipatory phase), and a sustained increase during active copulation (consummatory phase) [4] [30].

It seems, sexual behaviors belong to a category of natural occurring events with reward phenomena that are mediated by increased DA release in the nucleus accumbens. Increased mesolimibic DA during the preparatory and consummatory phases of sexual behavior in male rats could serve on both area one to reward ongoing sexual activity and to facilitate preparatory sexual behaviors that are elicited by primary or secondary sensory cues associated with a sexually receptive female [4].

DPP seems to act as a DA agonist. Our study showed that, DPP increased the plasma level of testosterone and estradiol [34]. Testosterone (T) not only has effect on erection but also, stimulates the synthesis and release of DA. Steroids indirectly influence the DA release via stimulating nitric oxide (NO) synthesis. NO is a soluble gas that acts both as a second messenger and as a neurotransmitter that is involves in male sexual functions including penile erection [48] and central control of sexual behavior [49]. NO is produced by NOS, which converts L-arginine into citrulline. In rodents, the expression of NOS in special regions is the control of sexual behavior and control of gonadal hormones. NO also plays a crucial role in intracavernous pressure and penile erection by acting on smooth muscle cells [50]. NO stimulates catecholamine release and inhibits its reuptake. Metabolites of testosterone (T) promote the copulation by up-regulating of NO production in brain which increases basal and stimulated DA release by female. In turn, DA facilitates genital reflex, sexual motivation and copulatory efficiency. $\mathrm{T}$ aromatizes and changes to estradiol (E) and/or reduces to Dihydrotestestrone (DHT) in brain that, these hormones regulate male sexual behaviors [51] [52]. The medial preoptic area (MPOA) is an important in- 
tegrative site for male sexual behavior. In male rats, DA releases in the MPOA shortly before and during copulation and the presence of $\mathrm{T}$ may be necessary for this effect [52]. These results suggest that Estrogen maintains normal basal levels of extracellular DA in the MPOA, which are sufficient for suboptimal copulation, and in female, Androgen is required for stimulating of DA release and for facilitation of ejaculation [53].

Our study showed that DA concentration of NAc increased markedly following replacing a new female. This support the idea that rats may have experience in sexual behavior. Experience plays an important role in the full development and efficiency of sexual behavior. Thus, sexual learning reduces the time to initiate sexual contact and to achieve ejaculation, as well as the amount of stimulation required to ejaculate [40]. Sexual experience also improves copulatory ability [54] [55], sharpens the olfactory interest of male rodents in female sexually related chemosignals [40] [56], and increases male fertility [57]. Few of the learning-induced changes in male sexual ability can be interpreted as experience dependent increases in sexual motivation, since males engage in sexual behavior more rapidly, ejaculate more often, and display shorter PEIs and increasing of DA [58]. Furthermore, sexual experience diminishes or eliminates the disruptive effect of a novel environment, seen in sexually naive males [39].

\section{Conclusion}

In conclusion, our results showed that DA concentration of nucleus accumbens increased in male rats following seeing and during their first encounter with a female in various phases of sexual behavior and this increase was higher in extract of treated rats in comparison with control. Thus, it seems that males were aroused sexually in mating cage. Introducing a female behind the screen (anticipatory phase) activated the sexual behavior and DA concentration in nucleus accumbens increased significantly due to female sex pheromones and olfactory cues [41]. During removing the screen (consummatory phase), a significant increase was observed in DA level. In this phase, it seems that increasing of DA must be due to genital motor activity. Overall, our data showed that copulation stimulates mesolimbic DA function in male rats and mounts with intromission are associated with increasing of DA. Increasing of DA, following administration of DPP suggests potential utility in managing sexual dysfunction and indicates that DPP can be used as a stimulator of sexual behavior and curing of male impotency (i.e. sexual arousal/erection disorders) and pre-mature ejaculation [34]. The present data suggest potential utility in managing sexual dysfunction. Its action may be due to the influence on sexual arousal and releasing of DA from nucleus accumbens. Effects of DPP may be due to the presence of steroids, alkaloids and flavonoids through a multitude of central and peripheral means [53] [59] [60].

\section{Acknowledgements}

The study was supported by vice chancellor for research of Tehran University of Medical Sciences, Tehran, IRAN. The authors wish to thank Mr. Ghasemi, Mr. Sohanaki (Ph.D. students of medical physiology-Tehran University of Medical Sciences) and Dr. Shahab Bohlooli and Dr. Perham Mohammadi (professors of Pharmacology-Ardabil University of Medical Sciences) for assisting in measuring of DA.

\section{References}

[1] Meisel, R.L. and Sachs, B.D. (1994) The Physiology of Male Sexual Behavior. In: Knobil, E. and Neill, J., Eds., Physiology of Reproduction, 2nd Edition, Raven Press, New York, 3-50, 70-100.

[2] Lal, S., Laryea, E. and Thavundayil, J.X. (1987) Apomorphine Induced Penile Tumescence in Impotent Patients: Preliminary Findings. Progress in Neuropsychopharmacology and Biological Psychiatry, 11, 235-242. http://dx.doi.org/10.1016/0278-5846(87)90066-2

[3] Giuliano, F. and Allard, J. (2001) Dopamine and Sexual Function. International Journal of Impotence Research, 13, S18-S28. http://dx.doi.org/10.1038/sj.ijir.3900719

[4] Elaine, M.H., John, W.M. and Satoru, S. (2004) Dopamine and Serotonin: Influences on Sexual Behavior. Physiology and Behavior, 83, 291-307. http://dx.doi.org/10.1016/j.physbeh.2004.08.018

[5] Barbeau, A. (1969) L-DOPA Therapy in Parkinson's Disease: A Critical Review of Nine Years' Experience. Canadian Medical Association Journal, 101, 791-800.

[6] Dula, E., Keating, W., Siami, P.F., Edmonds, A, O’Neil, J. and Buttler, S. (2000) Efficacy and Safety of Fixed-Dose and Dose Optimization Regimens of Sublingual Apomorphine versus Placebo in Men with Erectile Dysfunction. The Apomorphine Study Group. Urology, 56, 130-135. http://dx.doi.org/10.1016/S0090-4295(00)00575-6 
[7] Giuliano, F., Allard, J. and Apomorphine, S.L. (2002) (Uprima): Preclinical and Clinical Experiences Learned the First Central Nervous System-Acting ED Drug. International Journal of Impotence Research, 14, S53-S56. http://dx.doi.org/10.1038/sj.ijir.3900806

[8] Hull, E.M. and Dominguez, J.M. (2006) Getting His Act Together: Roles of Glutamate, Nitric Oxide, and Dopamine in the Medial Preoptic Area. Brain Research, 1126, 66-75. http://dx.doi.org/10.1016/j.brainres.2006.08.031

[9] Olivier, J.D.A., de Jong, T.R. and Dederen, P.J. (2007) Effects of Acute and Chronic Apomorphine on Sex Behavior and Copulation-Induced Neural Activation in the Male Rat. European Journal of Physiology, 576, 61-76.

[10] Tagliamonte, A., Fratta, W., Del Fiacco, M. and Gessa, G.L. (1974) Possible Stimulatory Role of Brain Dopamine in the Copulatory Behavior of Male Rats. Pharmacology, Biochemistry, and Behavior, 2, 257-260. http://dx.doi.org/10.1016/0091-3057(74)90061-6

[11] Rodriguez-Manzo, G. (1999) Yohimbine Interacts with the Dopaminergic System to Reverse Sexual Satiation: Further Evidence for a Role of Sexual Motivation in Sexual Exhaustion. European Journal of Pharmacology, 372, 1-8. http://dx.doi.org/10.1016/S0014-2999(99)00140-5

[12] Scaletta, L.L. and Hull, E.M. (1990) Systemic or Intracranial Apomorphine Increases Copulation in Long-Term Castrated Male Rats. Pharmacology, Biochemistry, and Behavior, 37, 471-475. http://dx.doi.org/10.1016/0091-3057(90)90015-A

[13] Ahlenius, S. and Larsson, K. (1990) Effects of Selective D1 and D2 Antagonists on Male Rat Sexual Behavior. Experientia, 46, 1026-1028. http://dx.doi.org/10.1007/BF01940663

[14] Pfaus, J.G. and Phillips, A.G. (1989) Differential Effects of Dopamine Receptor Antagonists on the Sexual Behavior of Male Rats. Psychopharmacology, 98, 363-368. http://dx.doi.org/10.1007/BF00451688

[15] Lopez, H.H. and Ettenberg, A. (2002) Exposure to Female Rats Produces Differences in c-Fos Induction between Sexually Naive and Experienced Male Rats. Brain Research, 947, 57-66. http://dx.doi.org/10.1016/S0006-8993(02)02907-4

[16] Lopez, H.H. and Ettenberg, A. (2002) Sexually Conditioned Incentives: Attenuation of Motivational Impact during Dopamine Receptor Antagonism. Pharmacology, Biochemistry, and Behavior, 72, 65-72.

[17] Baldwin, D. and Mayers, A. (2003) Sexual Side-Effects of Antidepressant and Antipsychotic Drugs. Advances in Psychiatric Treatment, 9, 202-210. http://dx.doi.org/10.1192/apt.9.3.202

[18] Missale, C., Nash, S.R., Robinson, S.W., Jaber, M. and Caron, M.G. (1998) Dopamine Receptors: From Structure to Function. Physiological Reviews, 78, 189-225.

[19] Hull, E.M., Bazzett, T.J., Warner, R.K., Eaton, R.C. and Thompson, J.T. (1990) Dopamine Receptors in the Ventral Tegmental Area Modulate Male Sexual Behavior in Rats. Brain Research, 512, 1-6. http://dx.doi.org/10.1016/0006-8993(90)91162-A

[20] Hull, E.M., Weber, M.S., Eaton, R.C., Dua, R., Markowski, V.P. and Lumley, L. (1991) Dopamine Receptors in the Ventral Tegmental Area Affect Motor, but Not Motivational or Reflexive, Components of Copulation in Male Rats. Brain Research, 55, 72-76. http://dx.doi.org/10.1016/0006-8993(91)90173-S

[21] Clement, P., Bernabe, J., Denys, P., Alexandre, L. and Giuliano, F. (2007) Ejaculation Induced by i.c.v. Injection of the Preferential Dopamine D(3) Receptor Agonist 7-Hydroxy-2-(di-N-propylamino)tetralin in Anesthetized Rats. Neuroscience, 145, 605-610. http://dx.doi.org/10.1016/j.neuroscience.2006.12.003

[22] Kitrey, N.D., Clement, P., Bernabe, J., Alexandre, L. and Giuliano, F. (2007) Microinjection of the Preferential Dopamine Receptor D(3) Agonist 7-Hydroxy-N,N-di-n-propylaminotetralin Hydrobromide into the Hypothalamic Medial Preoptic Area Induced Ejaculation in Anesthetized Rats. Neuroscience, 149, 636-641. http://dx.doi.org/10.1016/j.neuroscience.2007.06.051

[23] Woolley, S.C., Sakata, J.T. and Crews, D. (2004) Evolutionary Insights into the Regulation of Courtship Behavior in Male Amphibians and Reptiles. Physiology and Behavior, 83, 347-360. http://dx.doi.org/10.1016/j.physbeh.2004.08.021

[24] Schroeder, M.B. and Riters, L.V. (2006) Pharmacological Manipulations of Dopamine and Opioids Have Differential Effects on Sexually Motivated Song in Male European Starlings. Physiology and Behavior, 88, 575-584. http://dx.doi.org/10.1016/j.physbeh.2006.05.011

[25] Szczypka, M.S., Zhou, Q.Y. and Palmiter, R.D. (1998) Dopamine Stimulated Sexual Behavior in Testosterone Dependent Mice. Behavioral Neuroscience, 112, 1229-1235. http://dx.doi.org/10.1037/0735-7044.112.5.1229

[26] Hull, E.M. and Dominguez, J.M. (2007) Sexual Behavior in Male Rodents. Hormones and Behavior, 52, 45-55. http://dx.doi.org/10.1016/j.yhbeh.2007.03.030

[27] Zarrindast, M.R., Mamanpush, S.M. and Rashidy-Pour, A. (1994) Morphine Inhibits Dopaminergic and Cholinergic Induced Ejaculation in Rats. General Pharmacology, 25, 803-808. http://dx.doi.org/10.1016/0306-3623(94)90263-1 
[28] Hassan, W.A., El-kashlan, A.M. and Ehssan, N.A. (2012) Egyptian Date Palm Pollen Ameliorates Testicular Dysfunction Induced by Cadmium Chloride in Adult Male Rats. Journal of American Science, 8, 959-969.

[29] Miller, C.J., Dunn, E.V. and Hashim, I.B. (2003) The Glycaemic Index of Dates and Date/Yoghurt Mixed Meals. Are Dates the Candy that Grows on Trees? European Journal of Clinical Nutrition, 57, 427-430. http://dx.doi.org/10.1038/sj.ejcn.1601565

[30] Abbas, A.F. and Ateya, A.M. (2010) Estradiol, Esteriol, Estrone and Novel Flavonids from Date Palm Pollen. Australian Journal of Basic and Applied Sciences, 5, 606-614.

[31] Putnam, S.K., Du, J., Sato, S. and Hull, E.M. (2001) Testosterone Restoration of Copulatory Behavior Correlates with Medial Preoptic Dopamine Release in Castrated Male Rats. Hormones and Behavior, 39, 216-224. http://dx.doi.org/10.1006/hbeh.2001.1648

[32] Amine, E.S., Awa, O. and El-samad, M.A. (1969) Pharmacological Studies on Pollen Grains of Dates (Phoenix dactylifera). Phytochemistry, 8, 295-298.

[33] Bahmanpour, S., Talaei, T., Vojdani, Z., Panjehshahin, M.R., Poostapasand, A., Zareei, S. and Ghaeminia, M. (2006) Effect of Phoenix dactylifera Pollen on Sperm Parameters and Reproductive System of Adult Male Rats. Iranian Journal of Medical Sciences, 31, 208-212.

[34] Abedi, A., Parviz, M., Karimian, S.M. and Sadeghipour Rodsari, H.R. (2012) The Effect of Aqueous Extract of Phoenix dactylifera Pollen Grain on Sexual Behavior of Male Rats. Journal of Physiology and Pharmacology Advances, 2, 235-242.

[35] Paxinos, G. and Watson, C. (1997) The Rat Brain in Stereotaxic Coordinates. Academic Press, London.

[36] Agmo, A. (1997) Male Rat Sexual Behavior. Brain Research Protocols, 1, 203-209. http://dx.doi.org/10.1016/S1385-299X(96)00036-0

[37] Yakuba, M.T., Akanji, M.A., Oladiji, A.T. and Adesokan, A.A. (2008) Androgenic Potentials of Aqueous Extract of Massularia acuminate (G. Don) Bullock ex Hoyl. Stem in Male Wistar Rats. Journal of Ethnopharmacology, 118, 508-513. http://dx.doi.org/10.1016/j.jep.2008.05.020

[38] Yakubu, M.T., Akanji, M.A. and Oladiji, A.T. (2005) Aphrodisiac Potentials of the Aqueous Extract of Fadogia agrestis Stem in Male Albino Rats. Asian Journal of Andrology, 7, 399-404. http://dx.doi.org/10.1111/j.1745-7262.2005.00052.x

[39] Pfaus, J.G. and Wilkins, M.F. (1995) A Novel Environment Disrupts Copulation in Sexually Naive but Not Experienced Male Rats: Reversal with Naloxone. Physiology and Behavior, 57, 1045-1049. http://dx.doi.org/10.1016/0031-9384(94)00394-K

[40] Pfeiffer, C.A. and Johnston, R.E. (1994) Hormonal and Behavioral Responses of Male Hamsters to Females and Female Odors: Roles of Olfaction, the Vomeronasal System, and Sexual Experience. Physiology and Behavior, 55, 129138. http://dx.doi.org/10.1016/0031-9384(94)90020-5

[41] Brundege, J.M. and Williams, J.T. (2002) Differential Modulation of Nucleus Accumbens Synapses. Neurophysiology, 88, 142-151.

[42] Balfour, M.E., Yu, L. and Coolen, L.M. (2004) Sexual Behavior and Sex-Associated Environmental Cues Activate the Mesolimbic System in Male Rats. Neuropsychopharmacology, 29, 718-730. http://dx.doi.org/10.1038/sj.npp.1300350

[43] McGinnis, M.Y., Mirth, M.C., Zebrowski, A.F. and Dreifuss, R.M. (1989) Critical Exposure Time for Androgen Activation of Male Sexual Behavior in Rats. Physiology \& Behavior, 46, 159-165. http://dx.doi.org/10.1016/0031-9384(89)90249-7

[44] Losel, R.M., Falkenstein, E., Feuring, M., Schultz, A., Tillmann, H.C., Rossol-Haseroth, K. and Wehling, M. (2003) Nongenomic Steroid Action: Controversies, Questions, and Answers. Physiological Reviews, 83, 965-1016.

[45] Watson, C.S. and Gametchu, B. (2003) Proteins of Multiple Classes May Participate in Nongenomic Steroid Actions. Experimental Biology and Medicine, 228, 1272-1281.

[46] Zaki, A.K., Schmidt, J., Hammouda, F.M. and Adam, G. (1993) Steroid Constituents from Pollen Grain of Phoenix dactylifera. Planta Medica, 59, 613-614. http://dx.doi.org/10.1055/s-2006-959837

[47] Gauthaman, K. and Adaikan, P.G. (2008) The Hormonal Effects of Tribulus terrestris and Its Role in the Management of Male Erectile Dysfunction-An Evaluation Using Primates, Rabbit and Rat. Phytomedicine, 15, 44-54. http://dx.doi.org/10.1016/j.phymed.2007.11.011

[48] Andersson, K.E. (2001) Pharmacology of Penile Erection. Pharmacological Reviews, 53, 417-450.

[49] Zamble, A., Sahpaz, S., Brunet, C. and Bailleul, F. (2008) Effects of Microdesmis keayana Roots on Sexual Behavior of Male Rats. Phytomedicine, 15, 625-629. http://dx.doi.org/10.1016/j.phymed.2007.10.002

[50] Toda, N., Ayajiki, K. and Okamura, T. (2005) Nitric Oxide and Penile Erection Function. Pharmacology and Therapeutics, 106, 233-266. http://dx.doi.org/10.1016/j.pharmthera.2004.11.011 
[51] Moral1, G., Lemus, A.E. and Munguia, R. (1993) Induction of Male Sexual Behavior in the Rat by 7 Alpha-Methyl-19Nortestosterone, an Androgen that Does Not Undergo 5 Alpha-Reduction. Biology of Reproduction, 49, 577-581. http://dx.doi.org/10.1095/biolreprod49.3.577

[52] Nieoullon, A. and Coquerel, A. (2003) Dopamine: A Key Regulator to Adaptation, Emotion, Motivation and Cognition. Current Opinion in Neurology, 16, S3-S9. http://dx.doi.org/10.1097/00019052-200312002-00002

[53] Sahfiee, M. and Parivar, K. (2005) Effect of Pheonix dactylifera Extract on Testis and Spermatogenesis. MSc Thesis, Tarbiat Moalem University, Tehran.

[54] Pfaus, J.G., Kippin, T.E. and Centeno, S. (2001) Conditioning and Sexual Behavior: A Review. Hormones and Behavior, 402, 291-321. http://dx.doi.org/10.1006/hbeh.2001.1686

[55] Woodson, J.C. (2001) Including Learned Sexuality in the Organization of Sexual Behavior. Neuroscience and Biobehavioral Reviews, 26, 69-80.

[56] Swaney, W.T., Curley, J.P., Champagne, F.A. and Keverne, E.B. (2007) Genomic Imprinting Mediates Sexual Experience-Dependent Olfactory Learning in Male Mice. Proceedings of the National Academy of Sciences of the United States of America, 104, 6084-6089. http://dx.doi.org/10.1073/pnas.0609471104

[57] Domjan, M., Blesbois, E. and Williams, J. (1998) The Adaptive Significance of Sexual Conditioning: Pavlovian Control of Sperm Release. Psychological Science, 9, 411-415. http://dx.doi.org/10.1111/1467-9280.00077

[58] Sandroni, P. (2001) Aphrodisiacs Past and Present: A Historical Review. Clinical Autonomic Research, 11, $303-307$. http://dx.doi.org/10.1007/BF02332975

[59] Padashetty, S.A. and Mishra, S.H. (2007) Aphrodisiac Studies of Tricholepis glaberrima with Supportive Action from Antioxidant Enzymes. Pharmaceutical Biology, 45, 580-586. http://dx.doi.org/10.1080/13880200701501326

[60] Abedi, A., Parviz, M., Karimian, S.M. and Sadeghipour Rodsari, H.R. (2013) Aphrodsiac Activity of Aqueous Extract of Phoenix dactylifera in Male Rats. Advances in Sexual Medicine, 3, 28-34. http://dx.doi.org/10.4236/asm.2013.31006 